\title{
Ingênuos e órfãos pobres: a utilização do trabalho infantil no final da escravidão
}

\author{
MARIA APARECIDA C. R. PAPALI*
}

\begin{abstract}
Resumo: A exploração do trabalho do menor, do ingênuo e do órfão desvalido, filhos de libertas e mulheres solteiras pobres foi amplamente difundido entre muitos fazendeiros e membros da elite brasileira no final da escravidão. Ex-senhores de Taubaté, amparados pelo Judiciário, buscaram tutelar os filhos de suas escravas libertas no início de 1888, crianças e jovens que, da condição de ingênuos, foram lançados à condição de órfãos desamparados. Ao serem tutelados, tais menores eram encaminhados ao serviço doméstico ou ao trabalho na lavoura.

Abstract: The work exploration of the kids, of the ingenuous younger and of the abandoned orphan, children of the free and single poor women, was largely spread among many farmers and members of the Brazilian elite at the end of the slavery period. Ex-owneres of slaves in Taubaté, supported by the judiciary power, tutored the children of their free slave women. Kids and youngers changed their juridical condition from ingenuous children to abandoned orphans. After being tutored the kids were conducted to home or farming work.
\end{abstract}

Palavras-chave: Liberdade. Tutela. Órfãos.

Key words: Freedom. Tutelage. Orphans.

Desde a Colônia e estendendo-se ao Império, o Brasil manteve forte tradição de utilização da mão-de-obra infantil, tanto como recurso mantido no âmbito doméstico pelas famílias pobres, quanto em caráter de exploração ligado às elites, crianças em afazeres produtivos e desgastantes, nas lavouras, nas roças ou nas tarefas diárias das casas grandes. Ter "filhos de criação" foi estratégia bastante utilizada entre os mais pobres, como meio de relativizar a necessidade constante de mão-de-obra, nem sempre possível de

Professora na Universidade do Vale do Paraíba/UNIVAP. Doutora em História Social.

Estudos Ibero-Americanos. PUCRS, v. XXXIII, n. 1, p. 149-159, junho 2007 
ser suprida através da aquisição de trabalhadores escravizados (Marcílio, 1998, p. 134/160).

Para a criança abandonada, a filantropia religiosa contribuiu com a implementação da Roda dos Expostos, a partir do séc. XVIII, e com sua difusão entre as maiores cidades do Império, após a Independência. Muitas famílias, principalmente as mais pobres, iam às Rodas dos Expostos adotar "filhos de criação", os quais poderiam equilibrar a constante demanda por trabalhadores braçais, existente nestes setores da sociedade. Disseminou-se a figura das "mães criadeiras" e a tradição dos "filhos de criação" tornou-se mais forte no país (Venâncio, 1997, p. 191).

Instituições ligadas às Santas Casas, em parceria com as Câmaras Municipais, exerceram durante o Império um tipo de "filantropia pública" na assistência à criança abandonada. No entanto, não obstante a existência dessas instituições de acolhimento aos desvalidos, estima-se que, no Brasil colonial e mesmo durante o Império, apenas um pequeno percentual dessas crianças teriam sido assistidas por instituições. A grande maioria teria sido criada em casas de família, inaugurando um costume amplamente difundido no cotidiano brasileiro (Marcílio, 1998, p. 144).

A partir de 1850, com o fim do tráfico de escravos africanos, intensificação do tráfico interprovincial e crescente concentração de escravos no sudeste cafeeiro, algumas discussões têm início no país, em torno de como ficaria a "questão servil", o futuro trabalhador livre e a educação a ser ministrada aos filhos da emergente classe pobre livre, a qual compunha cada vez mais as fileiras dos trabalhadores despossuídos nacionais.

Nesse período, uma nova política de assistência à criança foi sendo implantada. Tem início em 1855 um projeto filantrópico de política pública, o qual teve como detonador o fim do tráfico, em 1850. A constatação de que a escravidão um dia chegaria ao fim mobilizou membros das classes privilegiadas brasileiras. Tal fato desencadeou, nas elites, um grande pavor de passarem por alguma escassez de mão-de-obra (Marcílio, 1998, p. 194).

Com o advento da Lei do Ventre Livre, em 1871, as preocupações em torno de como seria a atuação do futuro trabalhador brasileiro se intensificam e o filho da escrava tornou-se alvo de discussões acaloradas. Aprofunda-se o projeto filantrópico de amparo à criança abandonada, com a ingerência de médicos e sanitaristas, e com a atuação cada vez mais ativa de juristas sobre a vida de menores carentes. Estes, os juristas, tomaram as rédeas no controle sobre a "vadiagem" de crianças e menores desamparados. 
Outra questão que passou a ser alvo dos questionamentos das elites dirigentes do Império diz respeito à educação e instrução a ser ministrada aos mais pobres. Ventos modernizantes de inspiração liberal suscitavam tais debates. Alguns projetos de ampliação da instrução pública para viabilizar a educação popular foram iniciados nesse período (Papali, 2003, p. 123).

No entanto, tais iniciativas, ao pensarem a educação popular, o fizeram de forma discriminatória, uma vez que a escola projetada para os mais carentes foi concretizada somente em caráter primário, ministrando as chamadas "primeiras letras". Outras modalidades de ensino introduzidas nesse período foram os Institutos Profissionalizantes e as Colônias Orfhanológicas, dirigidas àqueles cujo destino social dificultava o acesso aos bancos escolares tradicionais. Em tais casas, esperava-se atender aos órfãos, filhos de pais pobres e menores "abandonados e ociosos". Os Institutos Profissionalizantes deveriam ministrar, além das primeiras letras e rudimentos básicos de aritmética, toda sorte de ensinamentos destinados ao aprendizado de ofícios manuais como serralheria, marcenaria, sapataria, entre outros.

Interessa-nos a aproximação dessas políticas educacionais com a potítica emancipacionista apregoada por essa época. Em decorrência da legislação abolicionista de 1871, e com as preocupações em torno das dificuldades futuras em se arregimentar mão-de-obra para a lavoura e para o serviço doméstico, algumas Sociedades Filantrópicas vão sendo criadas por juízes, advogados e até fazendeiros. Orfãos e menores desvalidos passam a ser preparados para o mercado de trabalho.

Torna-se relevante o fato de que tais discussões em torno do tipo de instrução a ser ministrada aos mais pobres tenha repercutido entre os fazendeiros, a ponto de compor a agenda de discussões dos Congressos Agrícolas de 1878. Em tais Congressos, enfatizou-se a necessidade de aliar o ensino primário ao agrícola, com o objetivo de atenuar a demanda por mão-de-obra nas fazendas. Uma das sugestões apresentadas pelos congressistas e que gerou polêmica na sociedade, foi a de que tais crianças e jovens, juntamente com os ingênuos, fossem encaminhados às fazendas, para receberem os ensinamentos agrícolas necessários (Schueler, 1999, p. 76).

A Lei de 1871 também incentivou o já impregnado costume brasileiro de se ter "filhos de criação", cuja mão-de-obra não se dispensaria mais tarde, ao dispor em seus artigos sobre a situação do filho da escrava, nascido livre de acordo com a respectiva lei. Como sabemos, tal legislação manteve o ingênuo junto ao senhor 
de sua mãe até a idade de 21 anos, reforçando laços tutelares já existentes na instituição escravocrata. Em uma legislação que vinha se formulando dentro das premissas do direito positivo e que já havia confrontado o poder senhorial ao estabelecer que o escravo poderia formar pecúlio e requerer sua liberdade "independente da vontade do senhor", o item relacionado ao futuro do ingênuo foi concebido de acordo com as leis costumeiras, ao adotar critérios já estabelecidos pela Legislação Orfanológica imperial, a qual se baseava nos costumes, tendo como respaldo as Ordenações Filipinas.

Em 1887, o governo imperial expediu um decreto notoriamente favorável à manutenção de ingênuos e órfãos pobres junto a fazendeiros e agricultores. Tal decreto recomendava que, na falta de Instituições Agrícolas e Profissionalizantes, os Juízes de Órfãos deveriam encaminhar tais menores para propriedades agrícolas, desde que os fazendeiros se comprometessem a assinar Termo de Tutela, encarregando-se a dar educação ao menor e trabalho compatível com sua idade (Papali, 2003, p. 128).

O papel dos Juízes de órfãos nas relações do mundo do trabalho já vinha de longa data na trajetória da escravidão brasileira. Aos Juízes de órfãos foram encaminhados os "africanos livres" apreendidos no país em 1831. Tais africanos foram designados a tutores, que os destinaram a trabalhar para o governo ou particulares, numa espécie de limbo jurídico por um "período de aprendizagem". Tal fato desencadeou o agravamento das relações do Brasil com a Inglaterra. Em 1857 a Inglaterra pressionava o Brasil para realizar um recenseamento a fim de detectar as "pessoas de cor" que ainda permaneciam no trabalho cativo. O Conselho de Estado não aprovou, aumentando as tensões do Brasil com a Inglaterra, atingindo o ápice em 1861 com a vinda de Christie, o qual insistia no esclarecimento sobre as condições de vida e trabalho a que estavam submetidos os "africanos livres" no país (Pena, 2001).

Pesquisas indicam a importância da justiça brasileira na formação de uma sociedade desigual e excludente, e historicamente ligada à política emancipacionista gradual da escravidão ao trabalho livre, tanto que a Reforma Judiciária de 1871 pode ser compreendida como política judiciária complementar ao projeto emancipacionista gradual, ao possibilitar a criação de um judiciário mais forte e autônomo, desvinculado do sistema policial (Koerner, 1998, p. 95/115).

Não obstante as políticas de incentivo para a criação de Institutos Profissionalizantes e Colônias Orfanológicas, mesmo que discriminatórias, tudo indica que a disputa pela mão-de-obra in- 
fantil tenha se acirrado entre os fazendeiros do sudeste cafeeiro, à medida que a campanha abolicionista avançava e as fugas em massa das fazendas não deixavam dúvidas quanto ao fim iminente da escravidão.

Evaristo de Morais observou indícios da existência da prática, em algumas localidades do sudeste cafeeiro, da "venda dos ingênuos" ou dos "serviços futuros" dos ingênuos, prática expressamente proibida na Regulamentação da Lei do Ventre Livre, em 1872 (Morais, 1968, p. 21).

Evidentemente, uma política se fazia no sentido de franquear acesso à mão-de-obra que fatalmente seria disponibilizada com o crescimento do filho da escrava. Em 1885, existiam ainda $400 \mathrm{mil}$ ou mais ingênuos matriculados. Desses, somente $0,1 \%$ teriam sido entregues ao governo, evidenciando o quanto os proprietários prezavam o valor dessa mão-de-obra (Conrad, 1978, p. 142/144).

Jornais pesquisados em algumas cidades do Vale do Paraíba paulista, como Taubaté, Guaratinguetá e São José dos Campos, entre 1878 e 1888, veicularam muitos artigos dedicados às crianças que andavam pelas ruas, jovens "vagabundos e ociosos". Entre discursos enfatizando a necessidade de disciplinar o trabalhador liberto, ou de procurar saídas urgentes pelas vias imigrantistas, algum espaço era sempre reservado aos menores que invadiam as ruas, discursos conclamando as autoridades a tomarem providências em relação ao futuro desses meninos.

Um desses artigos, veiculado no Diário Paulista de Taubaté, no exemplar de 4 de abril de 1888, o articulista (assinado ficticiamente: "Um Brasileiro") reclamava que os libertos e ingênuos também poderiam "prestar serviços" e ser "úteis" para o país. Ao afirmar que os ingênuos estariam "efetivamente livres e insubordinados", graças à ousadia dos abolicionistas, o articulista concluiu seus comentários dando o seguinte parecer: "entendemos que tais indivíduos (os ingênuos) deveriam ser postos sob a vigilância dos Juízes de Órfãos, e sujeitos a regras que os tornem cidadãos úteis. Será fácil consegui-lo impondo-lhes curadores e tutores, com a pena de serem remetidos aos asilos".

O jornal A Gazeta de Taubaté, que veiculou na cidade, entre 1878 e 1887, teve, desde as primeiras edições, a instrução pública como um de seus temas mais constantes. São relevantes também as discussões em torno da falta de cuidado com os órfãos da cidade, os quais, segundo o articulista, "jazem sem educação, na vagabundagem, viciando-se, sem que seus tutores tomem conhecimento".

No modesto periódico intitulado A Vida, de São José dos Campos, a preocupação com os filhos de escravas e mulheres po- 
bres em geral também se fazia presente, conforme ilustra o artigo de autor anônimo, veiculado em fevereiro de 1888:

Em todas cidades do Norte de São Paulo abundam crianças aos milhares. À falta de Liceu e de outras ocupações honestas, vivem aluvião de adolescentes numa perversidade medonha. As crianças, que representam o futuro da Pátria, desde que o mestre, o tutor, o pai, o Juíz de órfãos e autoridades não vigiem seus passos, em lugar de preparar-se para o trabalho e para a glória da Nação, preparam mendigos, criminosos e turbulentos, que só incomodam os tribunais. Neste período em que o elemento servil e toda a instituição negra perde o vigor e a queda é inevitável, é preciso preparar-mos braços que sirvão à agricultura, mecânica e belas-artes.

No pós-abolição, em agosto de 1888, passou a veicular-se em Taubaté o jornal O Noticiarista, circulando até 1895. O jornal fez grande campanha em prol do trabalho obrigatório para libertos, órfãos e "vagabundos" em geral, elogiando a ação da polícia ao apertar tais indivíduos, compelindo-os para o trabalho na lavoura ou dentro dos lares. Uma constante no jornal são os artigos sobre "meninos vagabundos", e o que as autoridades deveriam fazer em relação ao problema.

As liberdades incondicionais amplamente concedidas pelos senhores nos primeiros meses do ano de 1888, principalmente aqueles das regiões que mais resistiram à abolição, como o caso das cidades do Vale do Paraíba e Vale fluminense, foram primeiramente endereçadas às escravas desses senhores.

Logo no início de 1888, os jornais de Taubaté noticiaram a grande quantidade de alforrias incondicionais que passaram a ser concedidas pelos senhores aos seus escravos. Em Ações de Liberdade pesquisadas sobre a cidade de Taubaté, pôde-se verificar que, em 1888 as Ações de Liberdade incondicionais representavam quase a totalidade desses documentos, sendo que todas as Ações incondicionais pesquisadas em Taubaté foram concedidas pelos senhores às suas cativas. Nas Ações incondicionais da mencionada cidade, referentes ao ano de 1888, só as escravas foram premiadas pelos seus senhores (Papali, 2003).

Os filhos menores dessas escravas foram, em inúmeros casos, considerados órfãos, devido às brechas permitidas pela legislação emancipacionista de 1871, que manteve a questão do ingênuo em bases próximas da Legislação Orfanológica imperial, a qual preconizava serem considerados órfãos e passíveis de serem tutelados os filhos de mulheres solteiras pobres e miseráveis, categoria na qual se encontravam a maioria das escravas libertas. Muitas dessas 
mulheres, mesmo tendo família e companheiro fixo de muitos anos, não eram oficialmente casadas, requisito que passou a ser cada vez mais exigido pelos Juízes de Órfãos como comprovação de condição civil.

Com o 13 de maio, obviamente a legislação de 1871 não mais se sustentou, pela simples evidência da inexistência de escravos no país. No entanto, deixou resquícios de permanência, exatamente nas questões relacionadas ao ingênuo, questões estas que ficaram vinculadas ao direito costumeiro, campo fértil e propício à criação de brechas legais. Ao cair em desuso, a Lei de 1871 possibilitou a manutenção de certos "direitos adquiridos" pelos ex-senhores, possibilitando a manutenção do costume (Papali, 2002, p. 212).

Em pesquisa realizada no Arquivo de Taubaté, foram encontradas várias caixas contendo grande quantidade de Tutelas de órfãos emitidas durante o ano de 1888, principalmente recaídas sobre ingênuos. Foram pesquisadas 330 Ações de Tutela entre 1871 e 1895, no entanto grande quantidade dessas Ações concentram-se no ano de 1888, indicando um campo de tensão sendo instalado em torno do filho da escrava e de seu futuro como trabalhador. Foram contabilizados 427 órfãos tutelados durante as décadas pesquisadas, sendo a maior incidência durante o ano de 1888. Dos 427 órfãos tutelados na cidade de Taubaté, 279 concentram-se em 1888, diminuindo gradativamente nos anos subseqüentes.

Estudando-se as estratégias familiares de sobrevivência da família escrava no pós-abolição nas cidades de Campinas e Itu, e tendo como principal fonte as Tutelas de Órfãos das referidas cidades, Anna Gicelle Alaniz encontrou 112 órfãos tutelados nas cidades de Campinas e Itu durante o ano de 1888, considerado, pela autora, ano decisivo para as famílias negras e pobres das duas cidades (Alaniz, 1997, p. 58). Em Taubaté, só para o ano de 1888 foram tutelados 279 menores, a maioria ingênuos, ex-ingênuos ou filhos de mulheres solteiras pobres.

Das Ações Tutelares encontradas de 1888 e anteriores à Abolição, quase metade desses documentos continham a intenção dos senhores de dispensarem o serviço dos ingênuos. Uma vez alegada a desistência desses serviços, e ficando tais menores livres, tornavam-se sujeitos ao Direito Comum, e assim, sendo filhos de mães solteiras e "sem recursos para criá-los", conforme uma das alegações mais constantes, tais jovens passavam a necessitar de tutor, para "criá-los e educá-los". Tem-se como um dos exemplo dessas Tutelas o seguinte enunciado: 
Diz José Bonifácio Moreira, que tem em sua companhia, propriedade agrícola, no bairro do Taboão, três libertas, todas justas (assalariadas) e cada uma com um filho de idade de 8 anos - sendo o da primeira de nome Juvenal, o da segunda de nome Gabriel e o da terceira Cornelius; que estas libertas foram escravas do suplicante, tendo passado ao estado de liberdade, e como pela sua condição não lhes seja possível proporcionar um futuro melhor para estes órfãos, e como podem de uma hora para outra evadirem de sua casa, vem requerer a V.S. se digne nomear tutor para os mesmos órfãos (Tutela abril 1888/Arquivo Histórico de Taubaté).

Ao se dirigirem aos Juízes de Órfãos, muitos candidatos a tutoria requeriam tutela alegando que tais crianças e jovens precisavam da proteção de homens idôneos que pudessem educá-los nas primeiras letras, ensinar-lhes um ofício e encaminhá-los para um futuro melhor no mundo do trabalho.

No entanto, conforme pôde ser constatado, algumas condições para tanta generosidade permaneceram veladas nas entrelinhas dessas ações. A grande maioria das crianças e jovens tutelados não recebiam nem o ensinamento das primeiras letras, sendo encaminhados ao trabalho na lavoura ou ao serviço doméstico. Foi o início de uma grande demanda pela mão-de-obra disponibilizada por esses pequenos. Finda a escravidão, e com a abolição consolidada, o Judiciário de Taubaté se ocupou, daí em diante, com a grande concessão de Tutela de Órfãos (principalmente de exingênuos) que abarrotaram os cartórios da cidade, durante todo o desenrolar do ano de 1888 e nos anos posteriores.

As Ações Tutelares são documentos difíceis de serem divididos em categorias, sendo necessário compreendê-los mais pelo teor que contêm, do que propriamente tentar classificá-los. Mesmo assim, algumas diferenças estipuladas pelo Judiciário e pela legislação da época são importantes referências para uma melhor compreensão dessas fontes. Segundo o Processo Orfanológico de Pereira de Carvalho, vigente no final do XIX, as tutelas poderiam ser: tutelas testamentárias, tutelas legítimas ou tutelas dativas. Tutelas testamentárias seriam aquelas nas quais os tutores já seriam indicados em testamento; tutelas legítimas aquelas nas quais, por falta de testamento, a lei nomearia um tutor legítimo para o órfão (avós ou parentes próximos); e tutelas dativas aquelas que "na falta ou incapacidade de uns e outros, os tutores são nomeados pelo Juiz". Segundo jurisprudência de Pereira de Carvalho, as tutelas dativas seriam aplicadas aos incapazes, aos órfãos abandonados, aos miseráveis. 
Em Taubaté, das 330 Ações Tutelares pesquisadas para o período, apenas 29 são tutelas legítimas. A grande maioria - mais precisamente, $91,2 \%$ - dessas ações são Tutelas dativas, nas quais ficava a cargo do Juiz de Órfãos a escolha de um homem idôneo do lugar para servir de tutor aos órfãos pobres e desvalidos da cidade. Em relação às Tutelas dativas pesquisadas em Taubaté, para o período estudado, todas encontram-se denominadas como "Tutela", com exceção daquelas denominadas "Exoneração de Tutoria" ou algumas nas quais o termo "soldada" encontra-se acrescido à tutela. As maiores diferenças existentes entre esses documentos encontra-se no teor diferencial que muitas Ações de Tutela podem apresentar.

Algumas Ações Tutelares constituem-se em Ações rápidas, sumárias, contendo duas ou três páginas, no máximo, através das quais o próprio candidato à tutoria ou o Escrivão de Órfãos (ou Curador) entravam com uma petição ao Juiz de Órfãos, dizendo-se conhecedores de alguma criança ou jovem necessitados de tutoria, devido às condições precárias da mãe, fosse por pobreza e pela condição civil de solteira, pela conduta moral supostamente irregular ou pela liberdade recém-conquistada. Tais petições, eram imediatamente aceitas pelo juiz, lavrada a tutoria e, aparentemente, sem nenhum conflito.

No entanto, algumas Ações de Tutela prolongavam-se em algum tipo de disputa pelo órfão. Tais disputas podiam envolver outros candidatos à tutoria (geralmente interessados no trabalho do órfão), ou trazer o envolvimento das mães, pais ou parentes desses menores, empenhados em tirar tais crianças ou jovens de seus tutores, e levá-los para sua companhia. Alguns desses documentos encontram-se incompletos, constando apenas a petição inicial de mães ou pais pleiteando pela guarda de seus filhos (apesar de incompletos, algumas dessas petições constituem riquíssimos relatos de mães libertas), outros transformam-se em volumosos processos com o envolvimento de muitos sujeitos, tais como Escrivães de Órfãos, Curadores, Delegados de Polícia, Inspetores de Quarteirão, além de mães, pais, ou parentes dos órfãos tutelados. Muitas dessas Ações trazem também relatos de fuga de jovens tutelados, geralmente "seduzidos" pelas mães, parentes ou terceiros, ricas em detalhes do cotidiano das pessoas envolvidas, trazendo verdadeiros relatos de vida de libertos e homens pobres no pós-abolição.

Alguns Processos de Tutela foram movidos por terceiros em forma de denúncia contra o tutor, através das quais o suplicante alegava algum tipo de agressão física sofrida pelo tutelado, bus- 
cando persuadir o Juiz de órfãos da necessidade de se substituir o tutor do menor agredido. Tais ações, além de relatos de vida, trazem importantes depoimentos dos próprios menores, indicando riqueza de fonte ímpar.

Nas "Exonerações de Tutoria", importantes fontes de interpretação dos conflitos da época, o tutor dirige uma petição ao Juiz de Órfãos pedindo a remoção de seu cargo de tutor, tendo como justificativas a "insubordinação" dos tutelados, as freqüentes fugas dos menores ou a ingerência constante de mães ou parentes, nos passos desses órfãos. Algumas ações com pedido de exoneração de tutoria indicavam um certo desânimo de senhores tutores, alguns até explicitando que pediam exoneração pelo fato de seus tutelados "fugirem várias vezes de sua companhia". Pesquisando esses mesmos documentos nas cidades de Campinas e Itu, Alaniz também constatou alta incidência de fugas entre os menores tutelados, principalmente tratando-se de ex-ingênuos (Alaniz, 1997, p. 59/84).

Pela análise dessas Ações de Tutela de Taubaté pode-se verificar o grau de tensão que ainda permaneceu entre ex-senhores e libertos, no pós-abolição. Muitas Ações de Tutela prolongavam-se numa verdadeira disputa pelo órfão, fosse essa disputa iniciada por mães ou parentes, ou por outros candidatos a tutores, interessados na companhia do pupilo em questão. Ações de Tutela tensas e conflitantes que nos dão a medida da disputa pela mão-de-obra infantil vivenciada no final da escravidão e que teve como principal sujeito o filho livre da mulher escrava. Na cidade de Taubaté, evidências desse quadro deixaram um vasto registro das tensões experimentadas na época.

\section{Referências bibliográficas}

Alaniz, Anna Gicelle García. Ingênuos e libertos: estratégias de sobrevivência familiar em épocas de transição (1871-1895). Campinas: CMU/UNICAMP, 1997.

Carvalho, José Pereira de. Primeiras Linhas sobre o Processo Orphanologico. Rio de Janeiro: Jacintho Ribeiro dos Santos - Livreiro-Editor, 1915.

Conrad, Robert. Os últimos anos da escravatura no Brasil (1850-1888). Rio de Janeiro: Civilização Brasileira, 1978.

Koerner, Andrei. Judiciário e cidadania: na constituição da República brasileira. São Paulo: Hucitec, 1998.

Marcílio, Maria Luiza. História social da criança abandonada. São Paulo: Hucitec, 1998. 
Morais, Evaristo de. A campanha abolicionista (1879-1888). Brasília: UNB, 1986 (2a edição).

Papali, Maria Aparecida. Escravos, Libertos e Órfãos: a construção da liberdade em Taubaté (1871-1895). São Paulo: Annablume, 2003.

Papali, Maria Aparecida. A Legislação de 1871, o Judiciário e a Tutela de Ingênuos em Taubaté. Revista Justiça \& História, vol. 2, n. 3: Porto Alegre: Tribunal de Justiça do Estado do Rio Grande do Sul, 2002.

Pena, Eduardo Spiller. Pajens da casa imperial: jurisconsultos, escravidão e a lei de 1871. Campinas: Editora da UNICAMP, 2001.

Schueler, Alessandra F. Martinez de. Crianças e escolas na passagem do Império para a República. Revista Brasileira de História, São Paulo: ANPUH/Humanitas, vol. 19, n. 37, 1999.

Venâncio, Renato Pinto. Maternidade negada. In: Priori, Mary Del (org.); Bassanezi (coord.). História das Mulheres no Brasil. São Paulo: Contexto, 1997. 